\title{
Suggestions of Farmers to Mitigate the Ill Effects of Climate Change on Agriculture in Dharwad District of Karnataka, India
}

\author{
Huchhappa Gondali* and Dipak Kumar Bose
}

Department of Agricultural Extension \& Communication, Sam Higginbottom University of Agriculture, Technology and Sciences, Naini, Allahabad-211 007, U.P., India

*Corresponding author

\begin{tabular}{|c|}
\hline Keywords \\
\hline $\begin{array}{l}\text { Suggestion, Climate } \\
\text { change, Agriculture }\end{array}$ \\
\hline Article Info \\
\hline $\begin{array}{l}\text { Accepted: } \\
16 \text { February } 2018 \\
\text { Available Online: } \\
10 \text { March } 2018\end{array}$ \\
\hline
\end{tabular}

\section{Introduction}

Global Warming is the increase of Earth's average surface temperature due to effect of increase greenhouse gases, such as carbon dioxide emission from burning fossil fuels or from deforestation, which trap heat that would otherwise escape from Earth. The United Nations has identified two responses to climate change. Mitigation of climate change is by reducing the amount of greenhouse gases in the atmosphere and adaptation to the impacts of climate change. Practically, we are

\begin{abstract}
Climate changes, such as changes in temperatures, the amount, intensity and distribution of rainfall can have beneficial or adverse effects on world's agriculture. The present study was conducted in Dharwad districts of Karnataka state during 2016-17 to find out the suggestions of the respondents to mitigate the ill effects of climate change on agriculture. Descriptive research design was followed with a sample of 120 respondents selected randomly. The findings revealed that majority of the farmers suggested insurance has to be extended to all crops, followed by providing financial support for soil nutrient enrichment, implementation of weather related insurance scheme effectively was suggested by the above mentioned farmers. This was probably due to the lack of knowledge on scientific practices and adaptation options by the farmers. Incentives/support for increasing the green mase has to be given to all the crop produce based on cost of cultivation, subsidies/compensation has to be given for the crops to make up the cost of cultivation due to weather aberrations. This was probably due to price fluctuation in the market. To minimize the ill effects of climate change on agriculture proper training on scientific methods, demonstration and extension strate
government, research station and extension functionaries.

A B S T R A C T
\end{abstract}

unlikely to clean up the greenhouse gas situation entirely through mitigation efforts, at least reduce their further increase, thus some adaptation will be necessary. Both adaptation and mitigation are essential to reduce the impacts of climate change.

Some changes in climate will affect agriculture through their direct and indirect effects on crops, soil, livestock, fisheries and pest. Tropical countries are likely to be affected more compared to the countries situated in temperate regions. The burnt of 
environmental changes is expected to be very high in India due to greater dependence on agriculture, limited natural resources, alarming increase in human and livestock population changing pattern in land use and socioeconomic factors that pose a great threat in meeting the food, fiber, fuel and fodder requirement, There is a likelihood of considerable impact on agriculture land-use due to snow melt, availability of irrigation, frequency and intensity of inter and intraseasonal droughts and floods soil organic transformation, soil erosion and availability of energy as a consequence of global warming impacting agricultural production.

In order to understand how human beings would respond to climate change, it is essential to study people's perceptions of climate and the environment in general (Vedwan and Rhoades, 2001). Human expectations regarding weather and climate sometimes lead to perceptions of climate change which are not supported by observational evidences (Rebetcz, 2000). A better understanding of how farmers' perceive climate change, ongoing adaptation measures, and the factors influencing the decision to adapt farming practices is needed to craft policies and programmes aimed at promoting successful adaptation of the agricultural sector (Bryan et al., 2009).

\section{Materials and Methods}

The present investigation was conducted in Taluk Kundagol of Dharwad district which was selected purposively based on depending upon extent of climate variation. The study covered 12 villages and 120 respondents who had more than 15 years of farming experience selected randomly. Data were collected by using pre-tested interview schedule by the researcher himself. The data on socioeconomic aspects like education, age, family type, land holding, occupation, income, mass media exposure were collected. The information was also gathered through focused group discussion and observation methods. The collected data were coded, tabulated, classified and analysed by both descriptive and inferential statistics to draw the conclusion.

\section{Results and Discussion}

The results of the study with respect to socioeconomic profile of the respondents are presented in Table 1. Table 1 indicated that majority $(51.67 \%)$ respondents were middle aged followed by 29.17 per cent between 18 35 years, 19.16 per cent respondents age was above 51 years. The probable reason for such distribution might be that majority of the middle aged farmer's perceived agriculture as a profitable avenue. Majority of the respondents $(68.33 \%)$ were literate while 31.67 per cent were illiterate. Regarding of the land holding majority $(76.67 \%)$ of the respondents are marginal and small farmers.

About the annual income, it was found that majority $(66.67 \%)$ of the respondents comes under medium to semi medium income group, 20.00 per cent have high level of income, 52.50 per cent have medium level of mass media exposure respectively. Similar findings are also reported by Ahmad et al., (2013).

Table 2 indicates that the majority of the respondents valuable suggestion given by Insurance has to be extended to all crops $(85 \%)$ followed by Providing financial support for soil nutrient enrichment (81.67\%), Incentives/support for increasing the green manuring (77.5\%), Support price has to be given to all the crop produce based on cost of cultivation (72.5\%), Subsidies/compensation has to be given for the crops to make up the cost of cultivation due to weather aberrations $(69.17 \%)$. 
Table.1 Socio demographic profile of the respondents

\begin{tabular}{|c|c|c|c|}
\hline Sr. no & Personal profile & Frequency & Percentage \\
\hline \multicolumn{4}{|l|}{ Age } \\
\hline 1. & Young (Between 18 - 35 years) & 35 & 29.17 \\
\hline 2. & Middle (Between 36 - 50 years) & 62 & 51.67 \\
\hline 3. & Old (Above 51 years) & 23 & 19.16 \\
\hline \multicolumn{4}{|c|}{ Education } \\
\hline 1. & Illiterate & 38 & 31.67 \\
\hline 2. & Primary school $\left(1^{\text {st }}\right.$ to $\left.4^{\text {th }}\right)$ & 34 & 28.33 \\
\hline 3. & Middle $\left(5^{\text {th }}-7^{\text {th }}\right)$ & 25 & 20.83 \\
\hline 4. & High school $\left(8^{\text {th }}-10^{\text {th }}\right)$ & 12 & 07.50 \\
\hline 5. & PUC & 09 & 13.33 \\
\hline 6. & Graduate and above & 2 & 1.67 \\
\hline \multicolumn{4}{|c|}{ Land holding } \\
\hline 1. & Marginal farmers (Up to $1.0 \mathrm{ha}$ ) & 38 & 31.67 \\
\hline 2. & Small farmers (1.1 to $2.0 \mathrm{ha})$ & 54 & 45.00 \\
\hline 3. & Medium farmers ( 2.1 to 4 ha) & 24 & 20.00 \\
\hline 4. & Big farmers (More than 4 ha) & 4 & 3.33 \\
\hline \multicolumn{4}{|c|}{ Annual income } \\
\hline 1. & Low (up to Rs. 17,000/-) & 16 & 13.33 \\
\hline 2. & Medium (Rs. 17,001-34,000) & 42 & 35.00 \\
\hline 3. & Semi-medium (Rs. 34,001-51,000) & 38 & 31.67 \\
\hline 4. & High (above Rs. 51,000/-) & 24 & 20.00 \\
\hline \multicolumn{4}{|c|}{ Extension contact } \\
\hline 1. & Low $(<12)$ & 30 & 25.00 \\
\hline 2. & Medium (12-14) & 64 & 53.33 \\
\hline 3. & High $(>14)$ & 26 & 21.67 \\
\hline \multicolumn{4}{|c|}{ Mass media exposure } \\
\hline 1. & Low $(<17)$ & 25 & 20.83 \\
\hline 2. & Medium (17-21) & 63 & 52.50 \\
\hline 3. & $\operatorname{High}(>21)$ & 32 & 26.67 \\
\hline
\end{tabular}

Table. 2 Suggestions given by the respondents to mitigate the ill effects of climate change

\begin{tabular}{|c|c|c|c|}
\hline SI. No. & Farmers suggestions & $\mathbf{F}(\%)$ & Rank \\
\hline 1 & Early warning has to be given to the farmers about environmental changes & $56(46.67)$ & IX \\
\hline 2 & $\begin{array}{l}\text { Creating awareness to the farmers about appropriate adaptation measures against } \\
\text { climate change }\end{array}$ & $69(57.5)$ & VIII \\
\hline 3 & $\begin{array}{l}\text { Development department should ensure supply of production inputs at appropriate } \\
\text { time in the villages }\end{array}$ & $75(62.5)$ & VII \\
\hline 4 & $\begin{array}{l}\text { Subsidies/compensation has to be given for the crops to make up the cost of } \\
\text { cultivation due to weather aberrations }\end{array}$ & $83(69.17)$ & V \\
\hline 5 & Insurance has to be extended to all crops & $102(85)$ & I \\
\hline 6 & Providing financial support for soil nutrient enrichment & $98(81.67)$ & II \\
\hline 7 & Incentives/support for increasing the green manuring & $93(77.5)$ & III \\
\hline 8 & Support price has to be given to all the crop produce based on cost of cultivation & $87(72.5)$ & IV \\
\hline 9 & Creating awareness/support for adoption of organic farming technologies & $78(65)$ & VI \\
\hline
\end{tabular}


Creating awareness/support for adoption of organic farming technologies (65\%), Development department should ensure supply of production inputs at appropriate time in the villages $(62.5 \%)$, Creating awareness to the farmers about appropriate adaptation measures against climate change (57.5\%), Early warning has to be given to the farmers about environmental changes (46.67\%). Similar findings are also reported by Pande and Akermann (2010).

It is concluded from the present study that the majority respondents belongs from medium level of socio-economic status. They have suggested that insurance has to be extended to all crops, providing financial support for soil nutrient enrichment, incentives/support for increasing the green manuring, support price has to be given to all the crop produce based on cost of cultivation. They also suggested that subsidies/compensation has to be given for the crops to make up the cost of cultivation due to weather aberrations. Government should take proper steps on crop insurance, subsidies, financial, cost of cultivation price as well as time to time traing, demonstration and proper extension strategies should be followed to minimize the ill effect of climate change in agriculture.

\section{References}

Ahmad J, Alam D and Hassen S (2013) Impact of Climate Change on Agriculture and Food Security in India. pp. 131-136.

Bryan, E., Deressa, T. T., Gbetibouo, G. A. and Ringler, C., 2009, Adaptation to climate change in Ethiopia and South Africa: options and constraints. Environ. Sci. Policy, 12 (4): 413-426.

Pande, P. and Akermann, K., 2010, Adaptation of small scale farmers to climatic risks in India. Sustained India, B-4 GK II, New Delhi, India.

Rebetcz, M., 2000, Public expectations as an element of human perceptions of climate change. Climatic change, Springer, Netherlands 32: 495-509.

Vedwan, N. and Rhoades, R. E., 2001, Climate change in the western Himalayas of India: A study of local perceptions and response. Climate Res., 19: 109-117.

\section{How to cite this article:}

Huchhappa Gondali and Dipak Kumar Bose. 2018. Suggestions of Farmers to Mitigate the Ill Effects of Climate Change on Agriculture in Dharwad District of Karnataka, India. Int.J.Curr.Microbiol.App.Sci. 7(03): 1927-1930. doi: https://doi.org/10.20546/ijcmas.2018.703.228 